\title{
The effectiveness of natural supplements on prevention and treatment of delayed onset muscle soreness and markers of muscle damage: a review of literature
}

\author{
Brandie C. Cheshier, Bert H. Jacobson*
}

School of Kinesiology, Applied Health and Recreation, Oklahoma State University Stillwater, Oklahoma, USA

* Corresponding author: bert.jacobson@okstate.edu

\begin{abstract}
Objective. Unaccustomed or high-intensity eccentric exercise often leads to delayed onset muscle soreness (DOMS) that presents as pain, soreness, or swelling. Nonsteroidal anti-inflammatory medications (NSAIDs) are often used to treat DOMS. Due to the potential adverse effects of NSAIDs, commerically available supplements have been suggested as a potential alternative treatment of DOMS. The purpose of this review is to examine the effects of commerically available supplements on DOMS and markers of muscle damage and inflammation.

Method. Existing publications were examined and summarized regarding the effects of supplements such as curcumin, green tea extract, ginseng, ginger, branch chain amino acids, anatabine, pomegranate juice, and protease on DOMS and markers of both muscle damage and inflammation following eccentric exercise. Results. Consuming branched chain amino acids (BCAA), pomegranate, and curcumin appear to have the greatest effect in preventing and treating DOMS. Anatabine and ginseng do not appear to decrease markers of muscle damage, inflammation, or DOMS.

Conclusion. Consuming supplements before or after exercise with anti-inflammatory and analgesia properties may be just as effective as NSAIDs in treating and preventing DOMS. Further studies should be conducted to determine the long-term effects of commerically available supplements and the safest dosage that can be consumed for maximal benefits.
\end{abstract}

\section{Keywords}

delayed onset muscle soreness; supplements; markers of muscle damage; eccentric exercise

Dol

$10.14712 / 23366052.2021 .4$

C 2021 The Authors. This is an open-access article distributed under the terms of the Creative Commons Attribution License (http://creativecommons.org/licenses/by/4.0), which permits unrestricted use, distribution, and reproduction in any medium, provided the original author and source are credited. 


\section{INTRODUCTION}

Delayed onset muscle soreness (DOMS) is an overuse injury that occurs after unaccustomed or high-intensity eccentric exercise (Cheung, Hume, \& Maxwell, 2003), and can occur in novice and elite athletes alike. In individuals who are just beginning to exercise, DOMS can result in decreased motivation. The eccentric actions of plyometric exercise, squatting, jumping, downhill running, and the lowering phase of resistance training are all known to result in DOMS (Connolly, Sayers, \& McHugh, 2003). DOMS presents itself as pain, muscle soreness, swelling, and stiffness 8 to 24 hours post-exercise and peaks 24-48 hr following an unaccustomed bout of eccentric exercise and resolves within 10 days following exercise (Manimmanakorn et al., 2016; Mchugh, Connolly, Eston, \& Gleim, 1999; Meamarbashi, 2017).

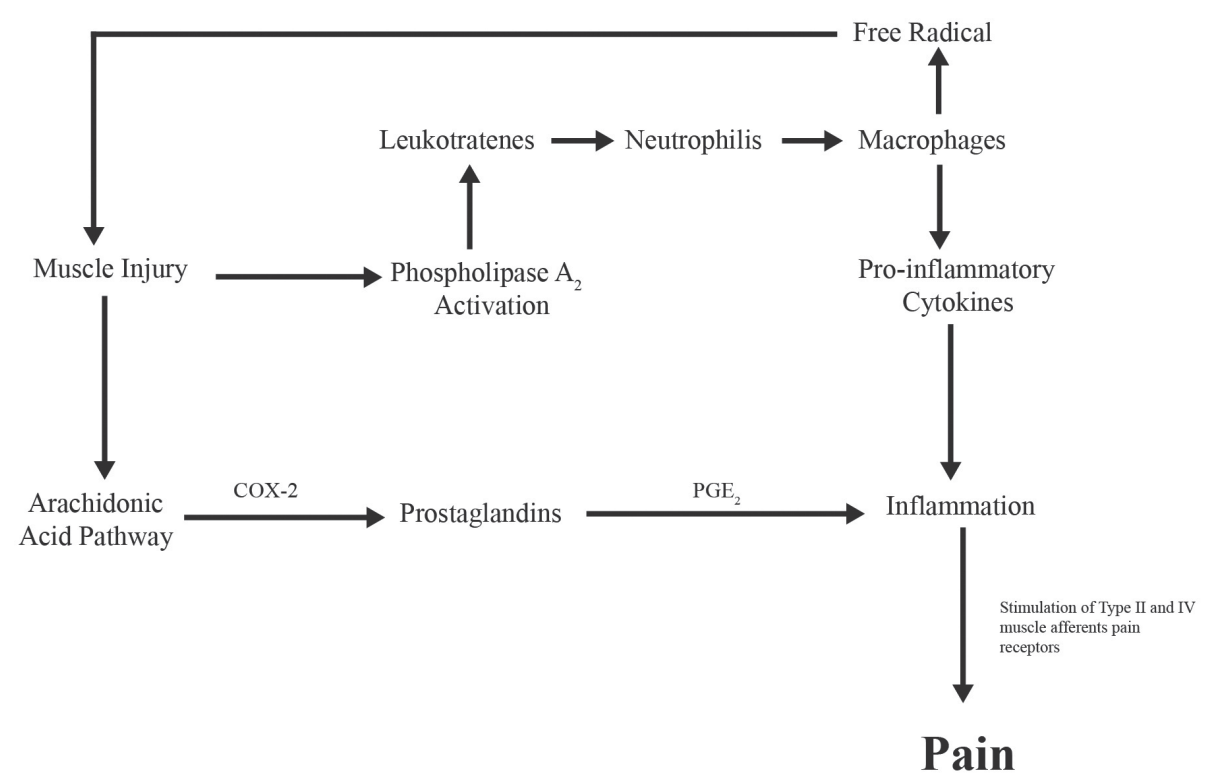

Figure 1 Schematic showing the possible sequence of injury leading to DOMS. COX-2, cycloxygenase; $\mathrm{PGE}_{2}$; prostaglandin $\mathrm{E}_{2}$

The underlying cause of DOMS is not fully understood. Most researchers agree that DOMS is caused by muscle damage (sarcomere disruption) and inflammation (Amalraj, Divya, \& Gopi, 2020; Hoseinzadeh, Daryanoosh, Baghdasar, \& Alizadeh, 2015) (Figure 1). During eccentric exercise, the sarcomeres become overstretched and fail to return to their resting length (Brooks, Fahey, \& Baldwin, 2005). The overstretched sarcomeres allow calcium to accumulate in the injured portion of the muscle activating proteases and phospholipase (Cheung, Hume, \& Maxwell, 2003; MacIntosh, Gardiner, \& McComas, 2006). The activation of proteases and phospholipase lead to the production of both prostaglandins and leukotrienes (MacIntosh, Gardiner, \& McComas, 2006). Neutrophils invade the injured area and increase vascular permeability, allowing fluids and intercellular components to enter the cells (MacIntosh, 
Gardiner, \& McComas, 2006). The fluid and intercellular components attract marcophages to invade the injuried area producing free radicals, proinflammatory cytokins and tumor nercosis factor-alpha (TNF- $\alpha)$ which further enhance muscle injury and stimulate type II and IV muscle afferent pain receptors, resulting in DOMS (Connolly, Sayers, \& McHugh, 2003; MacIntosh, Gardiner, \& McComas, 2006). Another pathway which is theorized to result in DOMS is the arachidonic acid pathway. Following muscle injury, arachidonic acid is released from the damaged cellular membranes (Maroon, Bost, Borden, Lorenz, \& Ross, 2006). Archidonic acid is quickly transfomed into prostaglandins $\left(\mathrm{PGE}_{2}\right)$ and thromboxanes through the enxyme cyclooxygenase (COX-1 or COX-2) (Maroon, Bost, Borden, Lorenz, \& Ross, 2006). COX-1 is a constitutive enzyme that protects the gastrointestinal lining and aids in platelet aggregation (Maroon, Bost, Borden, Lorenz, \& Ross, 2006). In comparison, COX-2 is activated during muscle damage and aids in producing inflammation and stimulating type II and IV pain receptors (Maroon, Bost, Borden, Lorenz, \& Ross, 2006).

Since the cause of DOMS is unknown, there is also a lack of knowledge for preventing DOMS. This lack of knowledge has led to multiple potential treatments, with mixed results (Cheung, Hume, \& Maxwell, 2003). Over the years, treatments such as stretching, massage, nonsteroidal anti-inflammatory medications (NSAIDs), ultraound, hyperabaric oxygen, and exercise have all been examined as potential solutions to DOMS (Cheung, Hume, \& Maxwell, 2003). Recently, athletes have increasingly sought natural remedies to treat pain and inflammation instead of NSAIDs, due to their potentially adverse effects within the gastrointestinal (stomach ulcers) and cardiovascular systems (blood clots leading to heart attacks and strokes). Many commerically available supplements are thought to have similar anti-inflammatory properties as NSAIDs, but without the adverse side effects. Some researchers believe that natural supplements may be an effective alternative to NSAIDs to control inflammation and oxidative stress induced by DOMS (Nakhostin-Roohi, Moradlou, Hamidabad, \& Ghanivand, 2016). Therefore, the purpose of this review is to examine the effects of commerically available supplements on DOMS and markers of muscle damage and inflammation. The supplements examined include: anatabine, branched chain amino acids. curcumin, ginger, ginseng, green tea extract, pomegranate juice, and protease.

\section{Anatabine}

Anatabine is a minor tobacco alkaloid with a comparable chemical structure to nicotine (Jenkins et al., 2013). Anatabine is a member of the Solanaceae (nightshade) family and found in green tomatoes, peppers, and eggplants (Paris et al., 2013). Anatabine is thought to have anti-inflammatory properties; however, little research has been done in regard to anatabine's potential to decrease inflammation. The exact mechanism in which anatabine influences inflammation is unknown. Researchers speculate that anatabine's anti-inflammatory effect involves altering the signal transducer and activator of transcription 3 (STAT3) and nuclear factor Kappa-B (NF-kB) pathways, which play a major role in pro-inflammatory cytokine production and activating inflammatory cells (Paris et al., 2013).

The most compelling research to support the claim that anatabine has anti-inflammatory properties was conducted with 32-week old mice. Paris el al. (2013) discovered that anatabine reduced the production of pro-inflammatory cytokines IL-6, 
IL-1, and TNF- $\alpha$. The researchers also examined the anti-inflammatory activity of anatabine in vitro and found that anatabine prevented IL-1 production and STAT3 and NF-kB phosphorylation induced by lipopolysaccharide (LPS) or TNF- $\alpha$ (Paris et al., 2013). These results supported the claim that anatabine decreases inflammation by alternating both the STAT3 and NF-kB pathways. Jenkins et al. conducted two studies in 2013 and 2014 examining the effects of 6-12 $\mathrm{mg}$ of anatabine prior to and subsequent to unilateral eccentric elbow flexion. The results of both of these studies revealed that anatabine did not have any effect on DOMS or markers of muscle damage (CK, TNF- $\alpha$, C-reactive protein (CRP), or myoglobin (MB)). The researchers concluded that the effectiveness of anatabine to block pro-inflammatory cytokines and decrease inflammation in humans after exercise was inconclusive (Jenkins et al., 2014) (Table 1).

\section{Branched chain amino acids}

Branched chain amino acids (BCAA) consist of leucine, isoleucine, and valine, which are three of the nine amino acids shown to be vital for protein synthesis and tissue repair (Leahy \& Pintauro, 2013). Unlike other essential acids that are catabolized in the liver, BCAA are primarily catabolized in skeletal muscle (Harper, Miller, \& Block, 1984). During exercise, the working skeletal muscles oxidize a greater proportion of BCAAs than any other amino acids (Shimomura, Yamamoto, \& Bajotto, 2006). Therefore, researchers speculate that BCAA may prevent muscle damage by promoting skeletal muscle protein synthesis and suppressing protein degradation, in addition to aiding in reactive oxygen species (ROS) scavenging (Kadowaki \& Kanazawa, 2003; Valerio, D'Antona, \& Nisoli, 2011).

Numerous studies have examined the effects of BCAA on DOMS and markers of muscle damage. Most agree that BCAA have the potential to decrease muscle damage and DOMS following eccentric exercise. Greer and colleagues (2007) conducted a study examining the effects of $5.0 \mathrm{~g}$ of BCAA five min prior and one hr after cycling for 90 min on a cycle ergometer at 55\% VO2max. The consumption of BCAA before and after an exhaustive bout of exercise decreased DOMS (24 hr post exercise) and lessened the increase in both creatine kinase (CK) and lactate dehydrogenase (LDH). Also, leg flexion torque was increased $48 \mathrm{hr}$ post exercise with no effect on leg extension torque. Another group of investigators found that long distance runners who consumed a 2,500 ml drink containing $0.8 \%$ BCAA during a three day intensive training program experienced a decrease in DOMS, fatigue, $\mathrm{CK}$, and lactate dehydrogenase (LDH) (Matsumoto et al., 2009). Others also found that BCAA consumption decreased DOMS after exercise (Asjodi, Khotbesara, Gargari, \& Izadi, 2018; Howatson et al., 2012; Leahy \& Pintauro, 2013; Nosaka, Sacco, \& Mawatari, 2006; Shimomura et al., 2010). Shimomura et al. (2010) examined the effects of consuming $100 \mathrm{mg} / \mathrm{kg}$ BCAA 15 min after completing 140 squats. Although DOMS declined, consuming BCAA 15 min after performing exercise did not influence CK. In comparison, Howatson et al. (2012) found plasma CK levels were significantly lower when national rugby and football players consumed $20 \mathrm{mg}$ of BCAA for 12 days (seven days prior and five days after 100 drop-jumps from a height of $0.6 \mathrm{~m}$ ). Asjodi, Khotbesara, Gargari, and Izadi (2018) discovered that $10 \mathrm{mg} / \mathrm{kg}$ of BCAA increased CK levels $72 \mathrm{hr}$ after a squat exercise (six sets at $75 \% 1 \mathrm{RM}$ ) while significantly decreasing LDH up to $48 \mathrm{hr}$ post 
exercise. In summary, there is substantial evidence to suggest that BCAA may be effective in preventing muscle damage, thereby decreasing DOMS and fatigue following exercise. The exact amount of BCAA that is recommended for maximal benefit has not been established (Table 2).

\section{Curcumin}

Curcumin has been used for centuries in both traditional Chinese and Indian medicine to reduce pain and inflammation (Nicol, Rowlands, Fazakerly, \& Kellett, 2015; Tanabe et al., 2019). Curcumin (diferuloylmethane) is extracted from the root of the curcumin plant (turmeric root) and is a natural polyphenolic substance with high anti-inflammatory and anti-oxidant properties (Delecroix, Abaidia, Leduc, Dawson, \& Dupont, 2017; Nicol, Rowlands, Fazakerly, \& Kellett, 2015; Singh \& Aggarwal, 1995). Curcumin is believed to have similar anti-inflammatory properties as NSAIDs such as ibuprofen and Celebrex, but without the major cardiovascular and gastrointestinal side effects (Nakhostin-Roohi, Moradlou, Hamidabad, \& Ghanivand, 2016). How curcumin influences inflammation is not agreed upon. However, it is believed that curcumin directly influences the activity of NF-kB, COX-2 or activator protein-1 (AP-1), which regulates the inflammation cascade (Davis et al., 2007). More specifically, curcumin may target NF-kB decreasing AP-1 binding to DNA decreasing the production COX-2, resulting in a blunted inflammation response to muscle injury following eccentric exercise (Singh \& Aggarwal, 1995; Thaloor, Miller, Gephart, Mitchell, \& Pavlath, 1999). The idea that curcumin inhibits NF-kB instead of COX- 2 is why many researchers believe the supplement has a decreased risk of potential adverse side effects that NSAIDs possess (Davis et al., 2007).

Researchers have found conflicting results on the effects of curcumin and DOMS. For instance, Nicol, Rowlands, Fazakerly and Kellett (2015) examined the effects of curcumin on DOMS, sport performance, and markers of muscle damage and inflammation. They discovered that when moderately trained men consumed $2.5 \mathrm{~g}$ of curcumin twice a day for five days (two days prior and three days post exercise), curcumin decreased DOMS and increased jump height $24 \mathrm{hr}$ and $48 \mathrm{hr}$ after exercise. In addition, they found that curcumin blunted the increase of creatine kinase (CK), and interleukin-6 (IL-6). Likewise, Nakhostin-Roohi, Moradlou, Hamidabad and Ghanivand (2016) discovered that $150 \mathrm{mg}$ of curcumin consumed immediately after eccentric exercise also decreased DOMS and markers of muscle damage (CK, alanine aminotransferase (ALT), and aspartate aminotransferase (AST)). In comparison, other researchers have shown that regardless of the dosage, curcumin did not have a significant effect on DOMS (Delecroix, Abaidia, Leduc, Dawson, \& Dupont, 2017; Jager, Purpuna, \& Kerksick, 2019; McFarlin et al., 2016; Tanabe et al., 2015).

While the effects of curcumin on DOMS are unclear, most researchers have shown that curcumin does decrease some markers of muscle damage (AST, ALT, CK) and inflammation (IL-6, interleukin-8 (IL-8) and TNF- $\alpha$. McFarlin et al. (2016) examined the effects of $400 \mathrm{mg}$ of curcumin daily (two days prior to and four days after exercise) and found that after eccentric leg press of $110 \%$ one repetition $\max (1-\mathrm{RM})$, curcumin significantly decreased CK, IL-6, IL-8 and TNF- $\alpha$. However, there was no significant difference between the curcumin and placebo groups in regard to DOMS and activities of daily living soreness. Others authors (Nakhostin-Roohi, Moradlou, 
Hamidabad, \& Ghanivand, 2016; Nicol, Rowlands, Fazakerly, \& Kellett, 2015; Tanabe et al., 2015; Tanabe et al., 2019) found similar results regarding the effects of curcumin on markers of muscle damage and inflammation. In comparison, Amalraj, Divya, and Gopi (2020) found that when $500 \mathrm{mg}$ of curcumin was consumed for three days after a 45 min downhill ( $-10 \%$ grade) run, CK was not significantly different from the placebo. Delecroix et al. (2017) also found that $6 \mathrm{~g}$ of curcumin combined with $60 \mathrm{mg}$ of peperline daily (two days prior and two days after exercise) did not result in a difference in CK from placebo.

Shortcomings of curcumin include its low bioavailability, poor solubility, and rapid elimination (Amalraj, Divya, \& Gopi, 2020; Tanabe et al., 2019). Therefore, ingesting curcumin only before exercise has shown little or no effect on muscle damage (Tanabe et al., 2019). Tanabe et al. conducted two studies in 2015 and 2019 on the effects of curcumin $(180 \mathrm{mg})$ before and after exercise. In both of the studies, DOMS was decreased when curcumin was consumed after exercise instead of before. The researchers also found that reduced CK lasted up to seven days after maximal elbow flexion only when curcumin was consumed following exercise (Tanabe et al., 2019). To gain maximal benefits from curcumin, researchers suggest it may be necessary to ingest curcumin continuously after exercise to keep curcumin concentrations in the blood elevated. (Tanabe et al., 2019). Overall, the general census in the literature is that curcumin can attenuate some, but not all, aspects of muscle damage and that more research should be done to determine the ideal dosage and consumption duration (Table 3).

\section{Ginger}

Ginger (zingiber officinale) is used in traditional Chinese medicine to treat arthritis, sprains, muscle aches, pain, and diabetes (Hoseinzadeh, Daryanoosh, Baghdasar, \& Alizadeh, 2015; Mashhadi et al., 2013). Ginger and its constituents are shown to have both analgesic and anti-inflammatory properties (Hoseinzadeh, Daryanoosh, Baghdasar, \& Alizadeh, 2015). The mechanism that is responsible for the analgesic and anti-inflammatory properties of ginger is through inhibiting COX-1 and COX2, decreasing pro-inflammatory cytokines (TNF- $\alpha$ and IL-6) and blocking leukotriene synthesis (Ali, Blunden, Tanira, \& Nemmar, 2008; Black \& O'Connor, 2010; Hoseinzadeh, Daryanoosh, Baghdasar, \& Alizadeh, 2015). Many studies have been conducted in an attempt to confirm the claimed benefits of ginger. Overall, the results of the reseaerch have been ambiguous. Mashhadi et al. (2013) had martial arts athletes consume $3 \mathrm{~g}$ of ginger daily six weeks before a sport-specific resistance training session during the competitive season. They found that DOMS was significantly lower when ginger was consumed before exercise, however ginger did not cause a significant decrease in IL-6. The authors suggested that $3 \mathrm{~g}$ may not have been large enough to have an influence on the pro-inflammatory cytokines. In comparison, Hoseinzadeh, Daryanoosh, Baghdasar, and Alizadeh (2015) compared the effects of $2 \mathrm{~g}$ of ginger extract in two conditions (one hr before a 20 -min step test and immediately after exercise) in untrained adults. Muscle soreness was significantly lower only when ginger was consumed prior to exercise. Plasma IL-6 levels were significantly lower in both conditions. A possibility for inconsistent results between the two studies mentioned in regard to IL-6 could lie within the training status of the participants. Mashhadi and colleagues (2013) recruited martial art athletes for their study while (Hoseinzadeh, 
Daryanoosh, Baghdasar, \& Alizadeh (2015) recruited untrained women. Plasma IL-6 is released during muscle contractions and is shown to be lower after long-term training because of the chronic muscle contractions (Nicklas et al., 2008). Therefore, it seems likely that trained individuals would need a higher dose of ginger to see any significant pro-inflammatory cytokines reductions. Manimmanakorn et al. (2016) examined the effects of Plai (zingiber cassumunar Roxb) on markers of muscle damage and DOMS. Plai is within the ginger family and contains powerful phytochemicals (Manimmanakorn et al., 2016). The participants applied either $7 \%$ or $14 \%$ Plai cream on their quadriceps for seven days post eccentric knee extension exercise. They found no effect of Plai cream on CK levels but DOMS was significantly lower after the application of the $14 \%$ Plai cream, but not after the $7 \%$ cream. Additionally, applying $14 \%$ Plai cream to the quadriceps preserved quadricep strength while applying the $7 \%$ did not decrease strength loss. While the aforementioned studies confirmed that ginger can reduce DOMS, other studies have shown the opposite. Black and O'Connor (2010) determined that $2 \mathrm{~g}$ of ginger for two days following unilateral eccentric elbow flexion exercise did not have an effect on DOMS, range of motion (ROM), or arm volume. Others (Matsummura, Zavorsky, \& Smoliga, 2015; Wilson, Fitzgerald, Rhodes, Lundstorm, \& Ingraham, 2015) agreed that ginger (2.2 g and $4 \mathrm{~g}$ respectively) had no effect on DOMS. Due to the conflicting results, further research needs to be conducted to verify the potential benefits of ginger after exercise (Table 4).

\section{Ginseng}

Ginseng (genus panax) is another supplement that has been used for thousands of years in traditional Chinese medicine to manage stress, relieve fatigue, and reduce pain and swelling (Caldwell et al., 2018; Pumpa, Fallon, Bensoussan, \& Papalia, 2013). The active ingredient in ginseng, saponins (ginsenosides), has shown the potential to block calcium influx into smooth muscle by activating $\mathrm{Na}^{+}-\mathrm{K}^{+}$ATPase, decrease intercellular calcium ion levels and heart rate (Chen, Chung, Li, Lin, \& Tzan, 2009). The influx of calcium ions into the working skeletal muscles is reported as a potential explanation for DOMS following an exhaustive bout of exercise (Pumpa, Fallon, Bensoussan, \& Papalia, 2013). If ginseng can potentially block excessive calcium influx into the working skeletal muscle, it may prevent or blunt DOMS following exercise (Pumpa, Fallon, Bensoussan, \& Papalia, 2013). Again, the mechanism in which ginseng acts upon is unclear.

The literature to support the claimed benefits of ginseng (reduction of pain, inflammation and fatigue) is sparse. Only a few studies have been conducted to examine the effects of ginseng on sports performance, soreness, or inflammation after exercise. Pumpa, Fallon, Bensoussan, and Papalia (2013) examined the effects of $400 \mathrm{mg}$ of ginseng after a downhill run $(-10 \%$ grade $)$ at $80 \% \mathrm{HR}_{\max }$. The authors found that DOMS was significantly lower $96 \mathrm{hr}$ post exercise in participants after consuming ginseng. However, ginseng did not influence markers of muscle damage such as CK, CRP, or $\mathrm{MB}$. It is interesting to note that in this particular study, both IL-6 and TNF- $\alpha$ were significantly higher after the consumption of ginseng compared to the control group. To explain these results, the authors suggested that ginseng may intensify the release or delay the clearance of TNF- $\alpha$ and impact the timing or expression of IL- 6 following exercise (Pumpa, Fallon, Bensoussan, \& Papalia, 2013). Hsu, Ho, Lin, Su, and Hsu 
(2005) studied the effects of $400 \mathrm{mg}$ of American ginseng on CK four weeks prior to running at $80 \%$ VO2max until volitional fatigue. The authors found that American ginseng significantly reduced CK immediately and up to $120 \mathrm{~min}$ following exercise. Lastly, Caldwell et al. (2018) compared the effects of consuming a high dose (960 mg) and low dose (160 mg) Korean ginseng, GINST15 (modified to have an increased bioavailability, 14 days prior to resistance training on DOMS and sport performance (reaction time and jump power). Consuming GINST15 decreased DOMS significantly in both groups. However, GINST15 did not improve reaction time nor jump power. As the results from these studies are mixed, the authors recommend that further research be conducted to identify the specific mechanism ginseng acts upon to decrease inflammation, soreness and fatigue, as well as the appropriate dosage required to achieve the aforementioned benefits (Table 5).

\section{Green tea extract}

Green tea extract is obtained from camellia sinensis and is rich in polyphenols such as epigallocatechin gallate, epicatechin, epigallocatechin, and epicatechin (da Silva, Machado, Souza, Mello-Carpes, \& Carpes, 2018). The properties of green tea extract make it a powerful anti-oxidant that gather free radicals such as superoxide hydroxyl (SOD) and hydrogen peroxide $\left(\mathrm{H}_{2} \mathrm{O}_{2}\right)$, and inhibits pro-oxidant enzymes (da Silva, Machado, Souza, Mello-Carpes, \& Carpes, 2018). The exact redox mechanism leading to exercise induced oxidative stress remains vague (He et al., 2016). Some researchers speculate that under stressful conditions such as eccentric exercise, the stimulation of xanthine oxidase (XO) contributes to the enhancement of reactive oxygen species (ROS) greater than the capacity of the anti-oxidant system to reduce ROS activity, resulting in oxidative stress and muscle cell damage (He et al., 2016). The damage to the muscle cells caused by oxidative stress decreases athletic performance and increases muscle soreness (Jowko et al., 2012). Increasing the anti-oxidant concentration by consuming green tea extract may offset fatigue and the accumulation of free radical production for a faster exercise recovery (Kerksick, Kreider, \& Willoughby, 2010). The anti-oxidant properties of green tea extract are believed to prevent ROS formation, thereby decreasing fatigue and preserving sport performance by inhibiting XO (Gomez-Cabrera, Domenech, \& Vina, 2008; Panza et al., 2008). There have been several studies examining the effects of green tea extract on measurements of oxidative stress. The results from these studies are conflicting. Furthermore, the exact dosage and duration that green tea needs to be consumed to combat oxidative stress and improve DOMS is unknown at this time. For instance, da Silva, Machado, Souza, Mello-Carpes, \& Carpes (2018) examined the effects of $500 \mathrm{mg}$ green tea extract over the course of 15 days post eccentric exercise. They found green tea extract did not improve markers of muscle damage (CK, lactate dehydrogenase (LDH)) or decrease oxidative stress (ROS, or ferric reducing antioxidant power (FRAP)). These results were in agreement with a study done by Jowko et al. (2012) in which the authors evaluated the effects of $640 \mathrm{mg}$ of green tea extract $1.5 \mathrm{hr}$ before a muscular endurance test. The researchers found that $640 \mathrm{mg}$ of green tea extract prior to exercise did not have an effect on markers of muscle damage (CK), oxidative stress (SOD, uric acid (UA) or total anti-oxidant capacity (TAC)). Other authors (Jowko, Dlugolecka, Makaruk, \& Cieslinski, 2015; Kerksick, Kreider, \& Willoughby, 2010) also found that green tea 
extract had no significant effect on markers of muscle damage and oxidative stress. In contrast, Panza et al. (2008) had 14 healthy adults consume $600 \mathrm{ml}$ of green tea daily, seven days before a bout of exhaustive bench press exercise. They found that FRAP was significantly higher after 14 days of consuming $600 \mathrm{ml}$ of green tea and XO was significantly decreased. The authors also discovered that CK and AST were significantly lower after exercise. The authors concluded that consuming at least $600 \mathrm{ml}$ of green tea may offer protection against oxidative stress after exercise. Due to the reduction in markers of muscle damage, the authors also suggested that the oxidative mechanism may play a role in the development of muscle damage following exercise. Herrlinger, Chirouzes, and Ceddia (2015) confirmed these results when they conducted a study examining the effects of $1,000 \mathrm{mg}$ or 2,000 $\mathrm{mg}$ of green tea extract daily for four days following a 40 min downhill run ( $-10 \%$ grade) at $65 \%$ VO2max. Both doses of green tea extract significantly reduced CK and LDH and enhanced FRAP.

To date, there have been three studies regarding the effects of green tea extract on DOMS. Kerksick, Kreider, and Willoughby (2010) found after 14 days of $1800 \mathrm{mg}$ of green tea extract following eccentric unilateral knee extension, DOMS was significantly decreased at $24 \mathrm{hr}$ post exercise, but markers of inflammation were not influenced by green tea extract. Similarly, Herrlinger, Chirouzes, and Ceddia (2015) also found that green tea $(2,000 \mathrm{mg})$ improved muscle soreness at both $48 \mathrm{hr}$ and $96 \mathrm{hr}$ after exercise. However, da Silva and colleagues (2018) found that muscle damage was minimized without any detectable significant changes in DOMS following 15 days of $500 \mathrm{mg}$ of green tea after performing calf raises to voluntary fatigue. Green tea extract may offer some protection against oxidative stress and reduce muscle damage and DOMS. Future research needs to determine the exact consumption dosage and duration required for green tea to have maximal benefits against oxidative stress and muscle soreness (Table 6).

\section{Pomegranate juice}

Pomegranate juice contains high levels of polyphenols and offers many health benefits and can aid in preventing and treating conditions such hypertension and dyslipidemia (Ammar et al., 2016). In addition, some believe that pomegranate juice has properties that can decrease both inflammation and oxidative stress (Ammar et al., 2016). Pomegranate extract (liquid or dry form) has recently become a popular alternative source for obtaining the polyphenols found in pomegranate juice (Ammar et al., 2018). One of the benefits of pomegranate juice or extract over other polyphenols such as green tea is the high bioavailability with an anti-oxidant activity three times higher than green tea, making it more effective in destroying free radicals, inhibiting cellular oxidative stress, and decreasing lipid peroxidation (Seeram et al., 2008). Pomegranate juice is thought to act similarly to green tea in that it inhibits cellular transcription factors NF-kB, TNF- $\alpha$, and COX-2, thereby preventing inflammation and pain (Adams et al., 2006; Afaq et al., 2005).

Although researchers have noted a beneficial effect of pomegranate juice, few have examined the potential effects of pomegranate juice after exercise. Lamb et al. (2019) examined the effects of a daily consumption of $500 \mathrm{ml}$ pomegranate juice four days prior and five days after unilateral eccentric elbow flexion. The authors found that nine days of pomegranate juice did not have an effect on elbow flexion strength, DOMS, 
ROM, or plasma CK levels. In comparison, Trombold, Barnes, Critchley, and Coyle (2010) investigated the effects of $100 \mathrm{ml}$ of ellagitanni (pomegranate extract) four days prior and five days post unilateral eccentric elbow flexion. Nine days of ellagitanni consumption significantly decreased DOMS $2 \mathrm{hr}$ after exercise and increased elbow flexor strength at 24 and $48 \mathrm{hr}$ following exercise. However, ellagitanni was not successful at influencing markers of muscle damage (CK, CRP) or pro-inflammatory cytokines (IL-6). Trombold conducted a second study (2011) and found that $500 \mathrm{ml}$ of pomegranate juice for 15 days (seven days prior and eight days after exercise) decreased DOMS in elbow flexors and improved elbow flexion strength up to seven days post unilateral maximal eccentric elbow flexion exercise.

In a study conducted by Amar and associates (2016), Olympic weight lighters consumed $500 \mathrm{ml}$ of pomegranate juice prior to training and another $450 \mathrm{ml}$ for two days following training. Pomegranate juice decreased knee extensor DOMS, rate of perceived exertion (RPE) and markers of muscle damage (CRP, CK, LDH and AST). In regard to elbow flexor DOMS, pomegranate juice had no effect. Based on the few studies conducted, it appears that pomegranate juice may be an effective treatment for muscle soreness and fatigue following exercise. However, more research needs to be completed to verify the effectiveness of pomegranate juice for recovery after exercise (Table 7).

\section{Protease}

Protease consists of a group of four biologically active enzymes (seline, cysteine, aspartic acid, and metalloproteases) that initiate protein catabolism through the hydrolysis of peptide bonds that link amino acids together in a polypeptide chain (Buford et al., 2009). Protease is believed to decrease inflammation and attenuate pain (Miller, Bailey, Barnes, Derr, \& Hall, 2004). How protease decreases inflammation remains unknown. It is hypothesized that protease reduces inflammation by blocking COX-2 stimulation to decrease edema and pain (Buford et al., 2009; Miller, Bailey, Barnes, Derr, \& Hall, 2004). A few studies have been conducted on the effects of protease on muscle damage and inflammation after exercise. Miller, Bailey, Barnes, Derr, and Hall (2004) studied the effects of protease on performance and DOMS after a 30 min downhill run ( $-10 \%$ grade). They discovered after four days of protease supplementation, DOMS was decreased 24 to $72 \mathrm{hr}$ post exercise. In addition, knee flexion power and torque were maintained after exercise with no change in agility run time, or knee extension torque. Shing and colleagues (2016) studied bromelain, a mixture of proteases obtained from pineapples, and its effect on highly trained road cyclists. The cyclists completed a cycle of 10 stages over the span of six days while consuming $1000 \mathrm{mg}$ of bromelain daily. Fatigue was decreased on day four only and the supplement did not influence CK, MB, or LDH. Beck et al. (2007) found similar results when 29 recreationally active men consumed a protease supplement that contained both $325 \mathrm{mg}$ of protease 6.0 and $340 \mathrm{mg}$ protease 4.5 four days after completing damaging eccentric forearm flexion exercise. While the protease supplement increased forearm flexion strength, it had no effect on DOMS, joint angle, or arm circumference. In addition, plasma $\mathrm{CK}$ and MB levels were not blunted after supplementation. Budfold et al. (2009) also found that 24 days of $5.828 \mathrm{mg}$ of protease had no effect on DOMS or some markers of muscle damage and inflammation (CK, SOD, IL-8, IL-10, IL-1, and TNF- $\alpha$ ). 
Intriguingly, protease did decrease three markers of inflammation (IL-6, IL-12 and COX-2) and improved quadriceps flexion strength. The authors concluded that while not all pro-inflammatory cytokines were decreased by protease, the decrease in IL-6 and IL-12, as well as COX-2, supported the concept that protease has the ability to decrease muscle inflammation and improve muscle function following exercise. Based on available evidence, it appears that protease may decrease inflammation and improve performance after a damaging bout of exercise. To gain a better insight in the potential post exercise benefits of protease, again, more research should be conducted (Table 8).

\section{DISCUSSION}

Finding ways to prevent and treat the negative effects of DOMS can maximize training performance in athletes, prevent injury, and help exercise novices maintain motivation (Nicol, Rowlands, Fazakerly, \& Kellett, 2015). The series of events that cause DOMS is unclear. However, researchers have come to the conclusion that both mechanical injury to the sarcomere and the inflammation cascade are key players in the development in DOMS (Cheung, Hume, \& Maxwell, 2003). Without knowing the exact cause of DOMS, finding the ideal treatment ramains difficult. Therefore, many proposed treatments for DOMS exsist (NSAIDs, massage, ultraound, hyperabaric oxygen, and exercise) and their effects on DOMS has produced mixed results (Cheung, Hume, \& Maxwell, 2003). NSAIDs are often used as the first line of defense in the treatment of inflammation and soreness following exercise. However, other than their potential adverse effects, NSAIDs may supress muscle protein synthesis (Mackey, 2013), thereby slowing the healing processes (Paulsen et al., 2010) following an injury, making them less than ideal. Many commerically available supplements have similar anti-inflammatory properties as NSAIDs without the possible adverse effects and remain safer alternativse for treating pain and inflammation. While they may be safer alternatives, as shown throuhgout this review, the exact mechanism in which these supplements target and the safest maximal dosages remain unknown.

It appears that many of the supplements reviewed may decrease DOMS following eccentric exercise, as well as decrease markers of muscle damage and inflammation. BCAA, pomegranate juice/extract and curcumin appear to have the greatest effect on DOMS. In comparision, anatabine and ginseng do not appear to have a significant effect on inflammation or DOMS following exercise. However, due to a lack of consistent study design and dosing for each supplement, it is diffuclt to draw a final conclusion on the effectiveness of these supplements on DOMS. Future research should examine the effects of consuming natural supplements on relieving the symptoms of DOMS on clinical populations such as those with diabetes and peripheral artery disease. In addition, for all populations, the safety of consuming natural supplements needs to be examined regarding adverse side effects, long-tem effects, as well as the optimal dosage. 


\section{REFERENCES}

Adams, L. S., Seeram, N. P., Aggarwal, B. B., Takada, Y., Sand, D., \& Heber, D. (2006). Pomegranate Juice, Total Pomegranate Ellagitannins, and Punicalogin Suppress Inflammatory Cell Signaling in Colon Cancer Cells. Journal of Agricultural and Food Chemistry, 54(3), 980-985.

Afaq, F., Malik, A., Syed, D., Maes, D., Matsui, M. S., \& Mukhtar, H. (2005). Pomegranate Fruit Extract Modulates UV-B-Mediated Phosphorylation of Mitogen-Activated Protein Kinases and Activation of Nuclear Factor Kappa B in Normal Human Epidermal Keratinocytes. Photochemistry and Photobiology, 81(1), 38-45.

Ali, B. H., Blunden, G., Tanira, M. O., \& Nemmar, A. (2008). Some Phytochemical, Pharacological and Toxicological Properties of Ginger (Zingiber officinale Roscoe): A Review of Recent Research. Food and Chemical Toxicology, 46(2), 409-420.

Amalraj, A., Divya, C., \& Gopi, S. (2020). The Effects of Bioavailable Curcumin (Cureit) on Delayed Onset Muscle Soreness Induced by Eccentric Continuous Exercise: A Randomized, Placebo-Controlled, Double-Blind Clinical Study. Journal of Medicinal Food, 23(5), 1-9.

Ammar, A., Bailey, S. J., Chtourou, H., Trabelsi, K., Turki, M., Hokelmann, A., Souissi, N. (2018). Effects of Pomegranate Supplementation on Exercise Performance and Post-Exercise Recovery in Healthy Adults: A Systematic Review. British Journal of Nutrition, 120(11), 1201-1216.

Ammar, A., Turki, M., Chtourou, H., Hammouda, O., Trabelsi, K., Kallel, C., ... Souissi, N. (2016). Pomegranate Supplementation Accelerates Recovery of Muscle Damage and Soreness and Inflammatory Markers After a Weightlifting Training Session. PloSONE, 11(10), $\mathrm{e} 0160305$.

Asjodi, F., Khotbesara, R. D., Gargari, B. P., \& Izadi, A. (2018). Impact of Combined or Single Supplementation of Branched-Chain Amino Acids on Delayed Onset Muscle Soreness and Muscle Damage Following Resistance Exercise. Progress in Nutrition, 20(2), 263-272.

Beck, T. W., Housh, T. J., Johnson, G. O., Schmidt, R. J., Housh, D. J., Coburn, J. W., ... Mielke, M. (2007). Effects of a Protease Supplement on Eccentric Exercise-Induced Markers of Delayed-Onset Muscle Soreness and Muscle Damage. Journal of Strength and Conditioning Research, 2(13), 661-667.

Black, C. D., \& O'Connor, P. J. (2010). Acute Effects of Dietary Ginger on Muscle Pain Induced by Eccentric Exercise. Phytotherapy Research, 24(11), 1620-1626.

Brooks, G. A., Fahey, T. D., \& Baldwin, K. M. (2005). Muscle Strength, Power and Flexibility. In: G. A. Brooks, T. D. Fahey, \& K. M. Baldwin (Eds.), Exercise Physiology: Human Bioenergetics and Its Application (pp. 456-491). New York, NY: McGraw-Hill.

Buford, T. W., Cooke, M. B., Redd, L. L., Hudson, G. M., Shelmadine, B. D., \& Willoughby, D. S. (2009). Protease Supplementation Improves Muscle Function After Eccentric Exercise. Medicine and Science in Sports and Exercise, 1908-1914.

Caldwell, L. K., DuPont, W. H., Beeler, M. K., Post, E. M., Barnhart, E. C., Hardesty, V. H., ... Kraemer, W. J. (2018). The Effect of a Korean Ginseng, GINST15, on Perceptual Effort, Psychomotor Performance, and Physical Performance in Men and Women. Journal of Sport Science and Medicine, 17(1), 92-100.

Chen, R. J., Chung, T.-Y., Li, F.-Y., Lin, N.-H., \& Tzan, J. T. (2009). Effect of Sugar Positions in Ginsenosides and their Inhibitory Potency on $\mathrm{Na}+\mathrm{K}+$-ATPase Activity. Acta Pharmaceutica Sinica, 1, 61-69.

Cheung, K., Hume, P. A., \& Maxwell, L. (2003). Delayed Onset Muscle Soreness: Treatment Strategies and Performance Factors. Journal of Sports Medicine, 33(2), 145-164.

Connolly, D. A., Sayers, S. P., \& McHugh, M. P. (2003). Treatment and Prevention of Delayed Onset Muscle Soreness. Journal of Strength and Conditioning Research, 17(1), 197-208. 
Da Silva, W., Machado, A. S., Souza, M. A., Mello-Carpes, P. B., \& Carpes, F. P. (2018). Effect of Green Tea Extract Supplementation on Exercise-Induced Delayed Onset Muscle Sorenes and Muscular Damage. Physiology and Behavior, 194, 77-82.

Davis, J. M., Murphy, E. A., Carmichael, M. D., Zielinski, M. R., Groschwitz, C. M., Brown, A. S., ... Mayer, E. P. (2007). Curcumin Effects on Inflammation and Performance Recovery Following Eccentric Exercise-Induced Muscle Damage. American Journal of Physiology: Regulatory. Integrative and Comparative Physiology, 292(6), R2168-R2173.

Delecroix, B., Abaidia, A. E., Leduc, C., Dawson, B., \& Dupont, G. (2017). Curcumin and Piperine Supplementation and Recovery Following Exercise Induced Muscle Damage: A Randomized Controlled Trial. Journal of Sports Science and Medicine, 16(1), 147-153.

Drobnic, F., Riera, J., Appendino, G., Togni, S., Franceschi, F., Valle, X., ... Tur, J. (2014). Reduction of Delayed Onset Muscle Soreness by a Novel Curcumin Delivery System: A Randomized, Placebo-Controlled Trial. Journal of the International Society of Sports Nutrition, 11(31), 3-10.

Gomez-Cabrera, M. C., Domenech, E., \& Vina, J. (2008). Moderate Exercise is an Antioxidant: Upregulation of Antioxidant Genes by Training. Free Radical Biology and Medicine, 44(2), 126-131.

Greer, B. K., Woodard, J. L., White, J. P., Arguello, E. M., \& Haymes, E. M. (2007). BranchedChain Amino Acid Supplementation and Indicators of Muscle Damage After Endurance Exercise. International Journal of Sport Nutrition and Exercise Metabolism, 17(6), 595-607.

Harper, A. E., Miller, R. H., \& Block, K. P. (1984). Branched-Chain Amino Acids Metabolism. Annual Review of Nutrition, 4, 409-454.

He, F., Li, J., Liu, Z., Chuang, C. C., Yang, W., \& Zuo, L. (2016). Redox Mechanism of Reactive Oxygen Species in Exercise. Frontiers in Physiology, 7, 486.

Herrlinger, K. A., Chirouzes, D. M., \& Ceddia, M. A. (2015). Supplementation with Polyphemolic Blend Improves Post-Exercise Strength Recovery and Muscle Soreness. Food and Nutrition Research, 59, 30034.

Hoseinzadeh, K., Daryanoosh, F., Baghdasar, P. J., \& Alizadeh, H. (2015). Acute Effects of Ginger Extract on Biochemical and Functional Symptoms of Delayed Onset Muscle Soreness. Medical Journal of the Islamic Republic of Iran, 29, 261.

Howatson, G., Hoad, M., Goodall, S., Tallent, J., Bell, P. G., \& French, D. N. (2012). Exercise-Induced Muscle Damage is Reduced in Resistance-Trained Males by Branched Chain Amino Acids: A Randomized, Double-Blind, Placebo Controlled Study. Journal of the International Society of Sport Nutrition, 9(20).

Hsu, C.-C., Ho, M.-C., Lin, L.-C., Su, B., \& Hsu, M.-C. (2005). American Ginseng Supplementation Attenuates Creatine Kinase Level Induced by Submaximal Exercise in Human Beings. World Journal of Gastroenterology, 34, 5327-5331.

Jager, R., Purpuna, M., \& Kerksick, C. M. (2019). Eight Weeks of a High Dose of Curcumin Supplementation May Attenuate Performance Decrements Following Muscle-Damaging Exercise. Nutrients, 11(1692), 1-14.

Jenkins, N. D., Housh, T. J., Cochrane, K. C., Bergstom, H. C., Traylor, D. A., Lewis, R. W., ... Cramer, J. T. (2014). Effects of Anatabine and Unilateral Maximal Eccentric Isokinetic Muscle Actions on Serum Markers of Muscle Damage and Inflammation. European Journal of Pharmacology, 728, 161-166.

Jenkins, N. D., Housh, T. J., Johnson, G. O., Traylor, D. A., Bergstrom, H. C., Cochrane, K. C., ... Cramer, J. T. (2013). The Effects of Anatabine on Non-Invasive Indicators of Muscle Damage: A Randomized, Double-Blind, Placebo-Controlled, Crossover Study. Journal of the International Society of Sport Nutrition, 10, 33.

Jowko, E., Dlugolecka, B., Makaruk, B., \& Cieslinski, I. (2015). The effect of Green Tea Extract Supplementation on Exercise-Induced Oxidative Stress Parameters in Male Sprinters. European Journal of Nutrition, 54(5), 783-791. 
Jowko, E., Sacharuk, J., Balasinska, B., Wilczak, J., Charmas, M., Ostaszewski, P., \& Charmas, R. (2012). Effect of a Single Dose of Green Tea Polyphenols on the Blood Markers of Exercise-Induced Oxidative Stress in Soccer Players. International Journal of Sport Nutrition and Exercise Metabolism, 22, 486-496.

Kadowaki, M., \& Kanazawa, T. (2003). Amino Acids as Regulators of Proteolysis. The Journal of Nutrition, 133(6), 2052S-2056S.

Kerksick, C. M., Kreider, R. B., \& Willoughby, D. S. (2010). Intramuscular Adaptations to Eccentric Exercise and Antioxidant Supplementation. Amino Acids, 39(1), 219-232.

Lamb, K. L., Ranchordas, M. K., Johnson, E., Denning, J., Downing, F., \& Lynn, A. (2019). No Effect of Tart Cherry Juice or Pomegranate Juice on Recovery from Exercise-Induced Muscle Damage in Non-Resistance Trained Men. Nutrients, 11(7), 1593.

Leahy, D. T., \& Pintauro, S. J. (2013). Branched-Chain Amino Acid Plus Glucose Supplement Reduced Exercise-Induced Delayed Onset Muscle Soreness in College-Age Females. ISRN Nutrition, 2013, 921972.

Mackey, A. L. (2013). Does an NSAID a Day Keep Satellite Cells at Bay? Journal of Applied Physiology, 115(6), 900-908.

MacIntosh, B. R., Gardiner, P. F., \& McComas, A. J. (2006). Injury and Repair. In: B. R. MacIntosh, P. F. Gardiner, \& A. J. McComas (Eds.), Skeletal Muscle: Form and Function (pp. 313-321). Champaign, IL: Human Kinetics.

Manimmanakorn, N., Manimmanakorn, A., Boobphachart, D., Thuwakum, W., Laupattarakasem, W., \& Hamlin, M. J. (2016). Effects of Zingiber Cassumunar (Plai Cream) in the Treatment of Delayed Onset Muscle Soreness. Journal of Integrative Medicine, 14(2), $114-120$.

Maroon, J. C., Bost, J. W., Borden, M. K., Lorenz, K. M., \& Ross, N. A. (2006). Natural Antiinflammatory Agents for Pain Relief in Athletes. Neurosurgeon Focus, 21(4), E11.

Mashhadi, N. S., Ghiasvand, R., Askari, G., Feizi, A., Hariri, M., Darvishi, L., ... Hajishafiee, M. (2013). Influence of Ginger and Cinnamon Intake on Inflammation and Muscle Soreness Enduced by Exercise in Iranian Female Athletes. International Journal of Preventive Medicine, 4, S11-S15.

Matsummura, M. D., Zavorsky, G. S., \& Smoliga, J. M. (2015). The Effects of Pre-Exercise Ginger Supplementation on Muscle Damage and Delayed Onset Muscle Soreness. Phytotherapy Research, 29(6), 887-893.

Matsumoto, K., Koba, T., Hamada, K., Sakurai, M., Higuchi, T., \& Miyata, H. (2009). Branched-Chain Amino Acid Supplementation Attenuates Muscle Soreness, Muscle Damage and Inflammation During an Intensive Training Program. Journal of Sport Medicine and Physical Fitness, 49(4), 424-431.

McFarlin, B. K., Venable, A. S., Henning, A. L., Best Sampson, J. N., Pennel, K., Vingren, J. L., \& Hill, D. W. (2016). Reduced Inflammatory and Muscle Damage Biomarkers Following Oral Supplementation with Bioavailable Curcumin. BBA Clinical, 5, 72-78.

McHugh, M. P., Connolly, D. A., Eston, R. G., \& Gleim, G. W. (1999). Exercise-Induced Muscle Damage and Potential Mechanisms for The Repeated Bout Effort. Sport Medicine, $27(3), 157-170$.

Meamarbashi, A. (2017). Herbs and Natural Supplements in the Prevention and Treatment of Delayed-Onset Muscle Soreness. Avicenna Journal of Phytomedicine, 7(1), 16-26.

Miller, P. C., Bailey, S. P., Barnes, M. E., Derr, S. J., \& Hall, E. E. (2004). The Effects of Protease Supplementation on Skeletal Muscle Function and DOMS Following Downhill Running. Journal of Sport Science, 22(4), 365-372.

Nakhostin-Roohi, B., Moradlou, A. N., Hamidabad, S. M., \& Ghanivand, B. (2016). The Effects of Curcumin Supplementation on Selected Markers of Delayed Onset Muscle Soreness (DOMS). Annals of Applied Sport Science, 4(2), 25-31. 
Nicklas, B. J., Hsu, F.-C., Brinkley, T. J., Church, T., Goodpaster, B. H., Kritchevsky, S. B., \& Pahor, M. (2008). Exercise Training and Plasma C-reactive Protein and Interleukin-6 in Elderly. Journal of the American Geriatrics Society, 56(11), 2045-2052.

Nicol, L. M., Rowlands, D. S., Fazakerly, R., \& Kellett, J. (2015). Curcumin Supplement Likely Attenuates Delayed Onset Muscle Soreness (DOMS). European Journal of Applied Physiology, 115(8), 1769-1777.

Nosaka, K., Sacco, P., \& Mawatari, K. (2006). Effects of Amino Acid Supplementation on Muscle Soreness and Damage. International Journal of Sport Nutrition and Exercise Metabolism, 16(6), 620-635.

Panza, V. S., Wazlawik, E., Schutz, G. R., Comin, L., Hecht, K. C., \& da Silva, E. L. (2008). Consumption of Green Tea Extract Favorable Affects Oxidative Stress Markers in WeightTrained Men. Nutrition, 24(5), 433-442.

Paris, D., Beaulieu-Abdelahad, D., Abdullah, L., Bachmeier, C., Ait-Ghezala, G., Reed, J., ... Mullan, M. (2013). Anti-Inflammatory Activity of Anatabine via Inhibition of STAT3 Phosphorylation. European Journal of Pharmacology, 698(1-3), 145-153.

Paulsen, G., Egner, M., Drange, M., Langberg, H., Benestad, B., Fjeld, J. G., ... Raastad, T. (2010). A COX-2 Inhibitor Reduced Muscle Soreness, But Does Not Influence Recobery and Adaptation After Eccentric Exercise. Scandinavian Journal of Medicine and Science in Sports, 20(1), e195-e207.

Pumpa, K. L., Fallon, K. E., Bensoussan, A., \& Papalia, S. (2013). The Effects of Panax Notoginseng on Delayed Onset Muscle Soreness and Muscle Damage in Well-Trained Males: A Double Blind Randomized Controlled Trial. Complementary Therapies in Medicine, 21(3), 131-140.

Seeram, N. P., Aviram, M., Zhang, Y., Henning, S. M., Feng, L., Dreher, M., \& Heber, D. (2008). Comparison of Antioxidant Potency of Commonly Consumed Polyphenol-Rich Beverages in United States. Journal of Agricultural and Food Chemistry, 56(4), 1415-1422.

Shimomura, Y., Inaguma, A., Watanabe, S., Yamamoto, Y., Muramatsu, Y., Bajotto, G., ... Mawatari, K. (2010). Branched-Chain Amino Acid Supplementation Before Squat Exercise and Delayed-Onset Muscle Soreness. International Journal of Sport Nutrition and Exercise Metabolism, 20(3), 236-244.

Shimomura, Y., Yamamoto, G., \& Bajotto, G. (2006). Nutraceutical Effects of Branched-Chain Amino Acids on Skeletal Muscle. Journal of Nutrition, 136(2), 529S-532S.

Shing, C. M., Chong, S., Driller, M. W., \& Fell, J. W. (2016). Acute Protease Supplementation Effects on Muscle Damage and Recovery Across Consecutive Days of Cycle Racing. European Journal of Sport Science, 16(2), 206-212.

Singh, S., \& Aggarwal, B. (1995). Activation of Transcription Factor NF-kB is Supressed by Curcumin (Diferulolymethane). The Journal of Biomedical Chemistry, 270(50), 24995-25000.

Stauber, W. T., Fritz, V. K., Dahlmann, B., \& Reinauer, H. (1988). Immunoflourescent Localization of an Alkaline Proteinase in Skeletal Muscle from Diabetic Rats. Basic and Applied Histochemistry, 20, 345-352.

Tanabe, Y., Chino, K., Ohnishi, T., Ozawa, H., Sagayama, H., Maeda, S., \& Takahashi, H. (2019). Effects of Oral Curcumin Ingested Before or After Eccentric Exercise on Markers of Muscle Damage and Inflammation. Scandinavian Journal of Medicine \& Science in Sports, 29(4), 524-534.

Tanabe, Y., Chino, K., Sagayama, H., Lee, H., Ozawa, H., Maeda, S., \& Takahashi, H. (2019). Effective Timing of Curcumin Ingestion to Attenuate Eccentric Exercise-Induced Muscle Soreness in Men. Journal of Nutritional Science and Vitaminology, 65(1), 82-89.

Tanabe, Y., Maeda, S., Akazawa, N., Zempo-Miyaki, A., Choi, Y., Ra, S.-G., ... Nosaka, K. (2015). Attenuation of Indirect Markers of Eccentric Exercise-Induced Muscle Damage by Curcumin. European Journal of Physiology, 115(9), 1949-1957. 
Thaloor, D., Miller, K. J., Gephart, J., Mitchell, P. O., \& Pavlath, G. K. (1999). Systemic Administration of the NF-kB Inhibitor Curcumin Stimulates Muscle Regeneration After Tramatic Injury. American Journal of Physiology-Cell Physiology, 2, C320-C329.

Trombold, J. R., Barnes, J. N., Critchley, L., \& Coyle, E. F. (2010). Ellagitannin Consumption Improves Strength Recovery 2-3d after Eccentric Exercise. Medicine and Science in Sports and Exercise, 42(3), 493-498.

Trombold, J. R., Reinfeld, A. S., Casler, J. R., \& Coyle, E. F. (2011). The Effect of Pomegranate Juice Supplementation on Strength and Soreness After Eccentric Exercise. Journal of Strength and Conditioning Research, 25(7), 1782-1788.

Valerio, A., D’Antona, G., \& Nisoli, E. (2011). Branched-Chain Amino Acids, Mitochondrial Biogenesis and Healthspan: An Evolutionary Perspective. Aging, 3(5), 464-478.

Wilson, P. B., Fitzgerald, J. S., Rhodes, G. S., Lundstorm, C. J., \& Ingraham, S. J. (2015). Effectiveness of Ginger Root (Zingiber officinale) on Running-Induced Muscle Soreness and Function: A Pilot Study. International Journal of Athletic Therapy \& Training, 20(6), 44-50. 


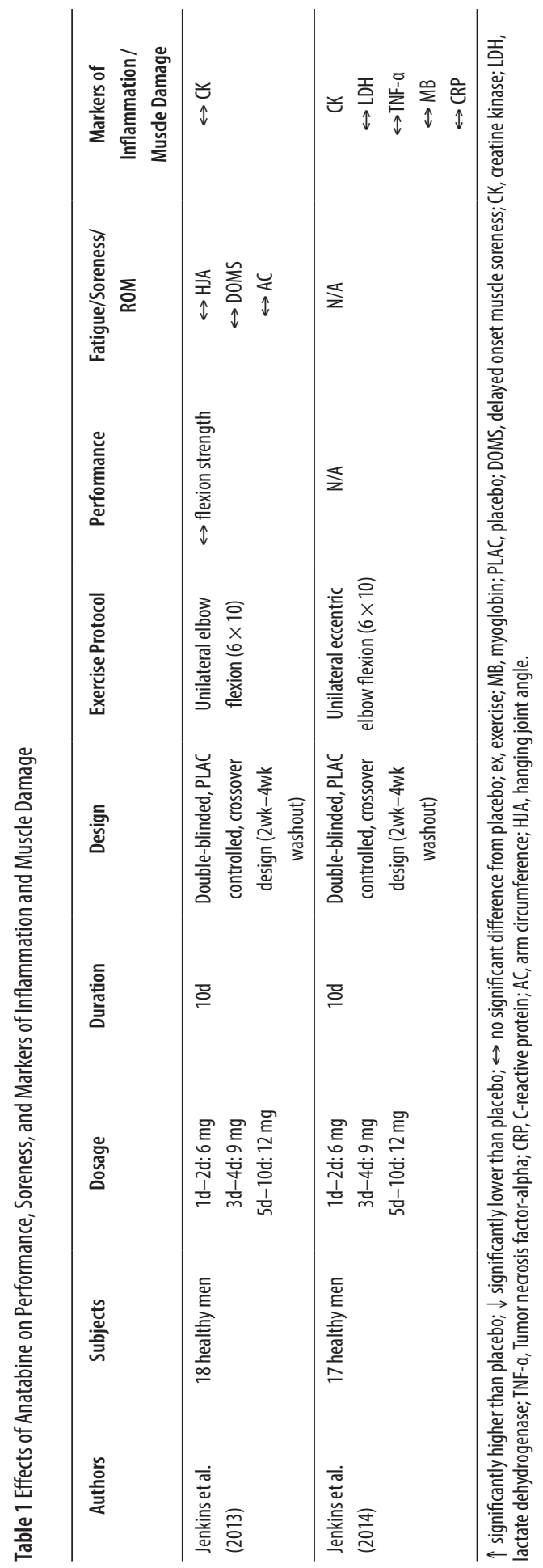




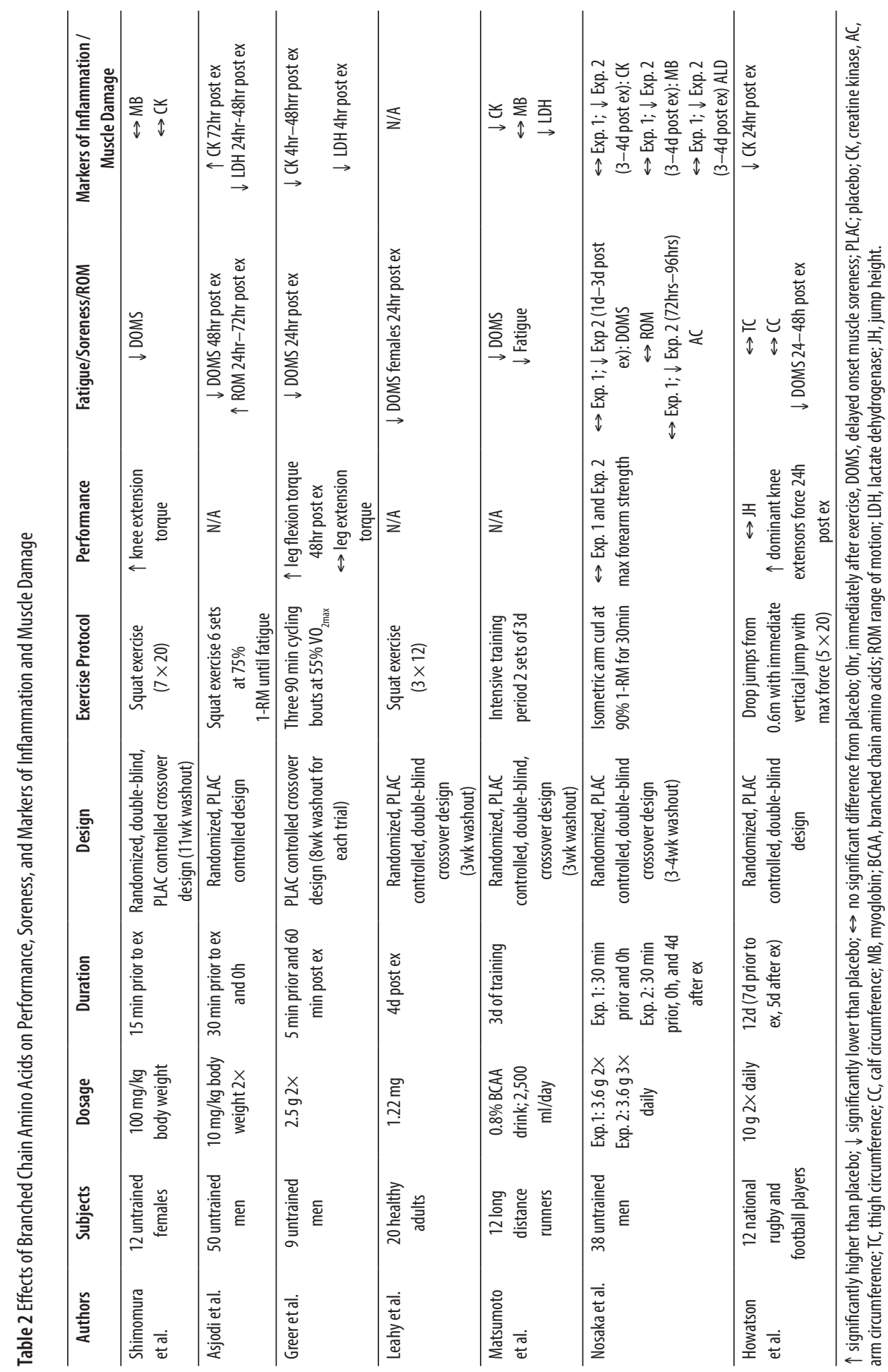




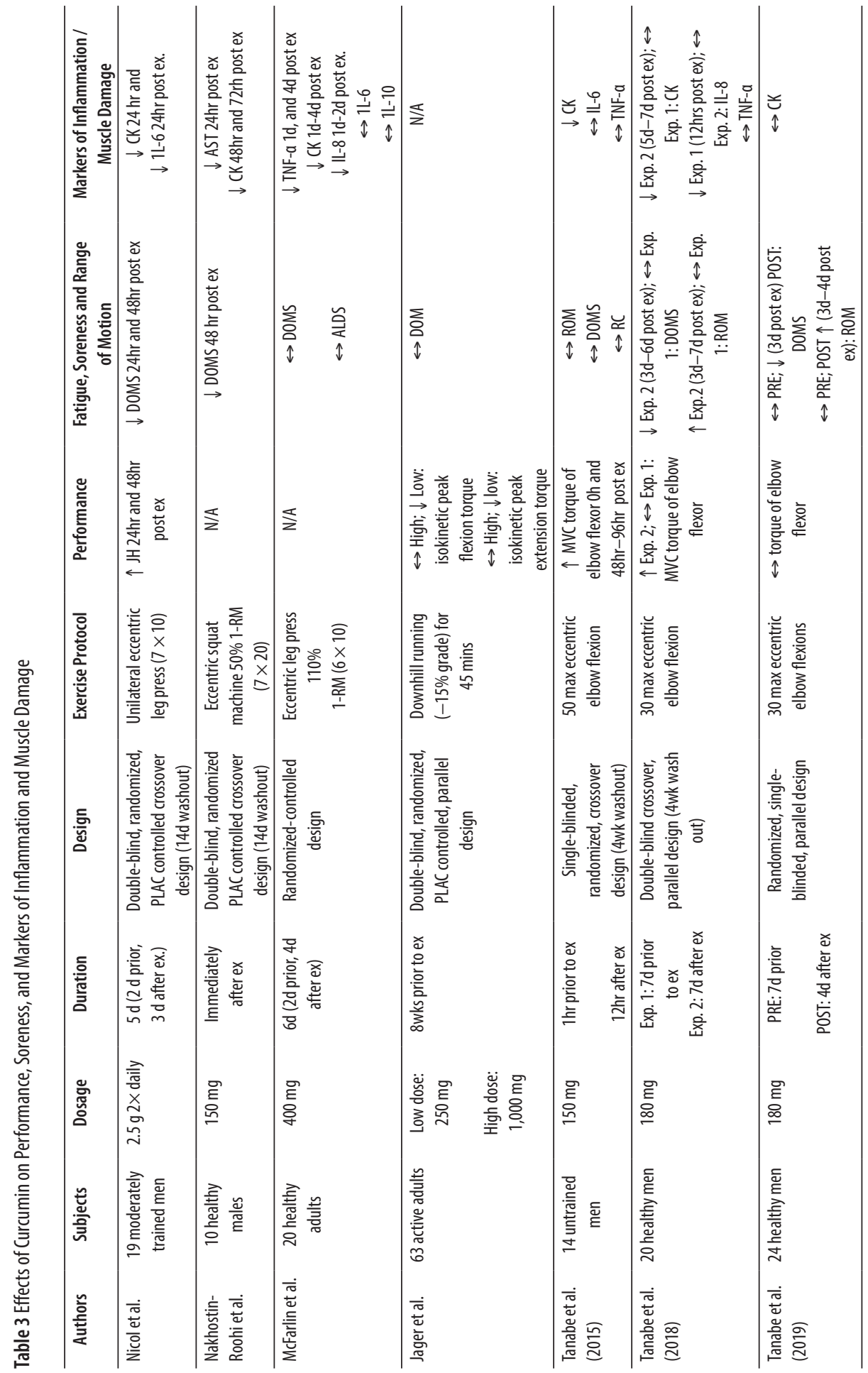




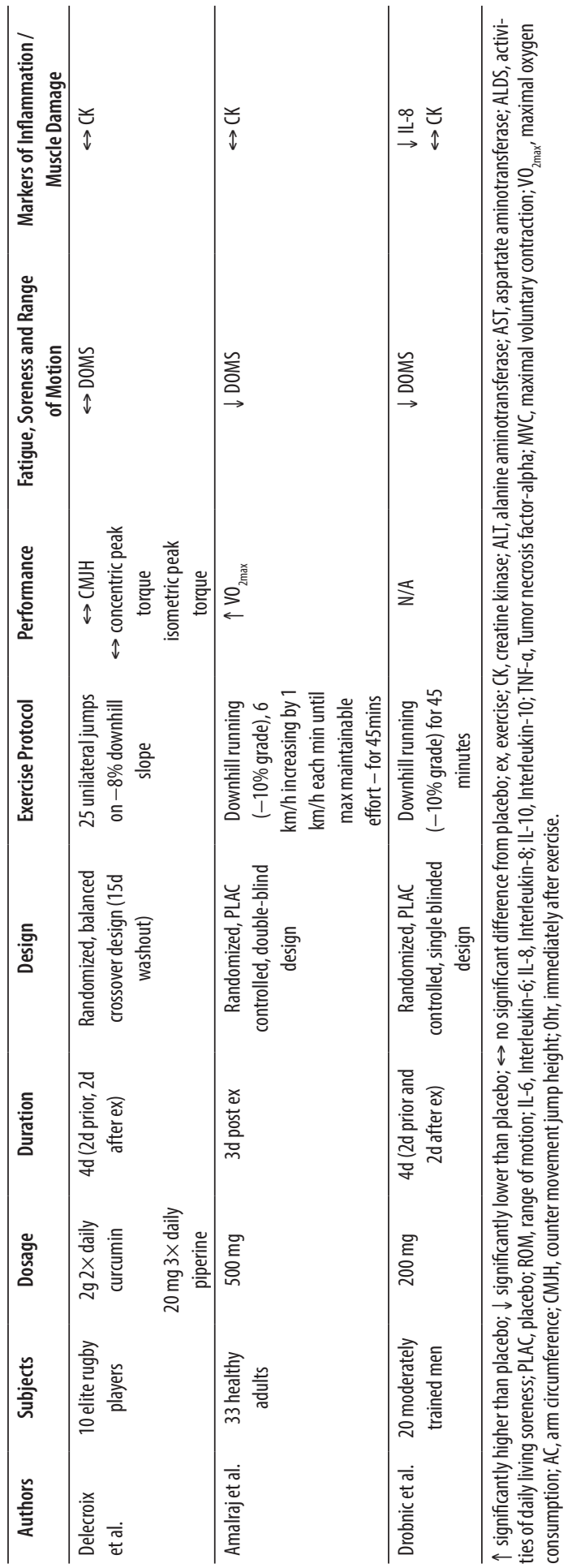




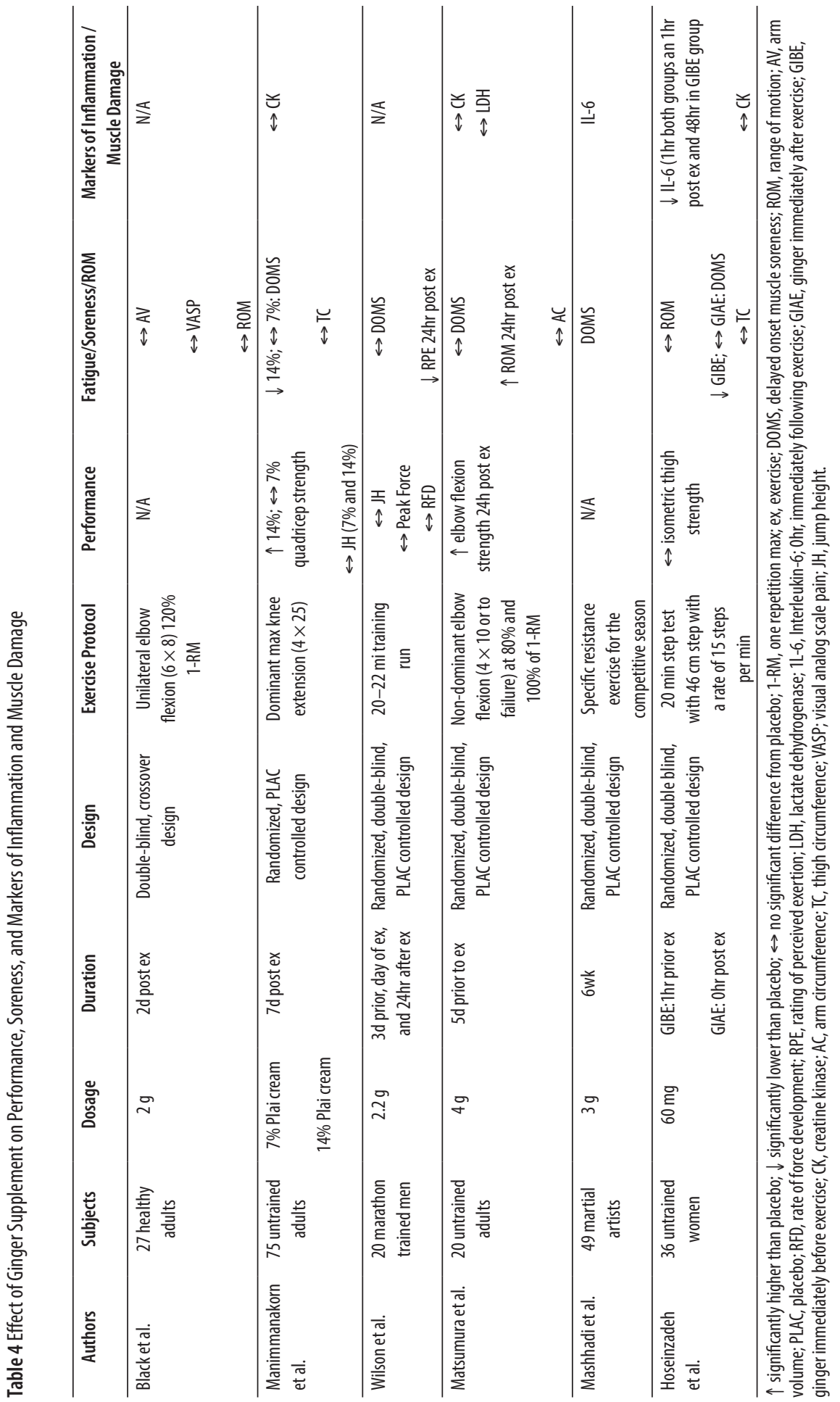




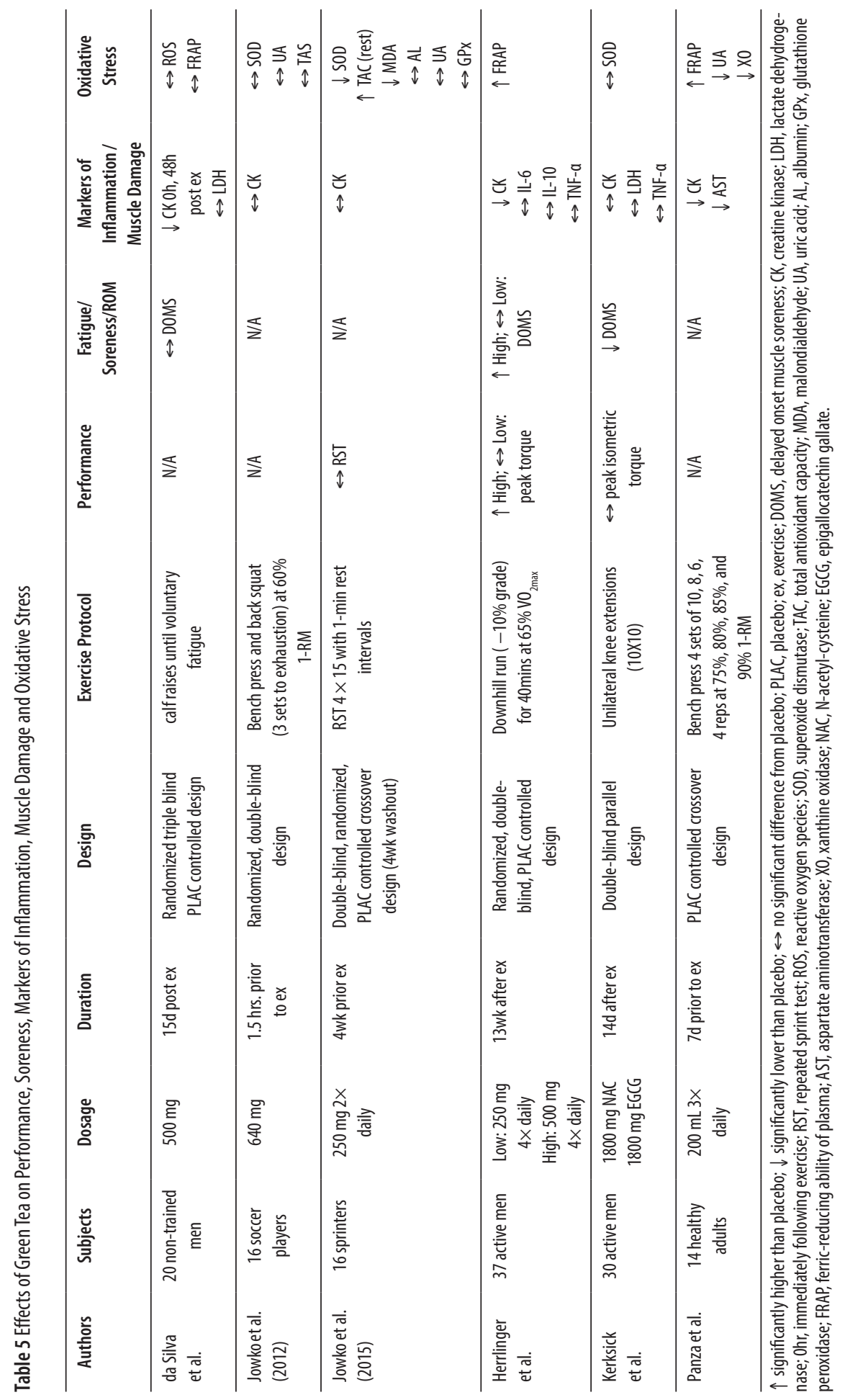




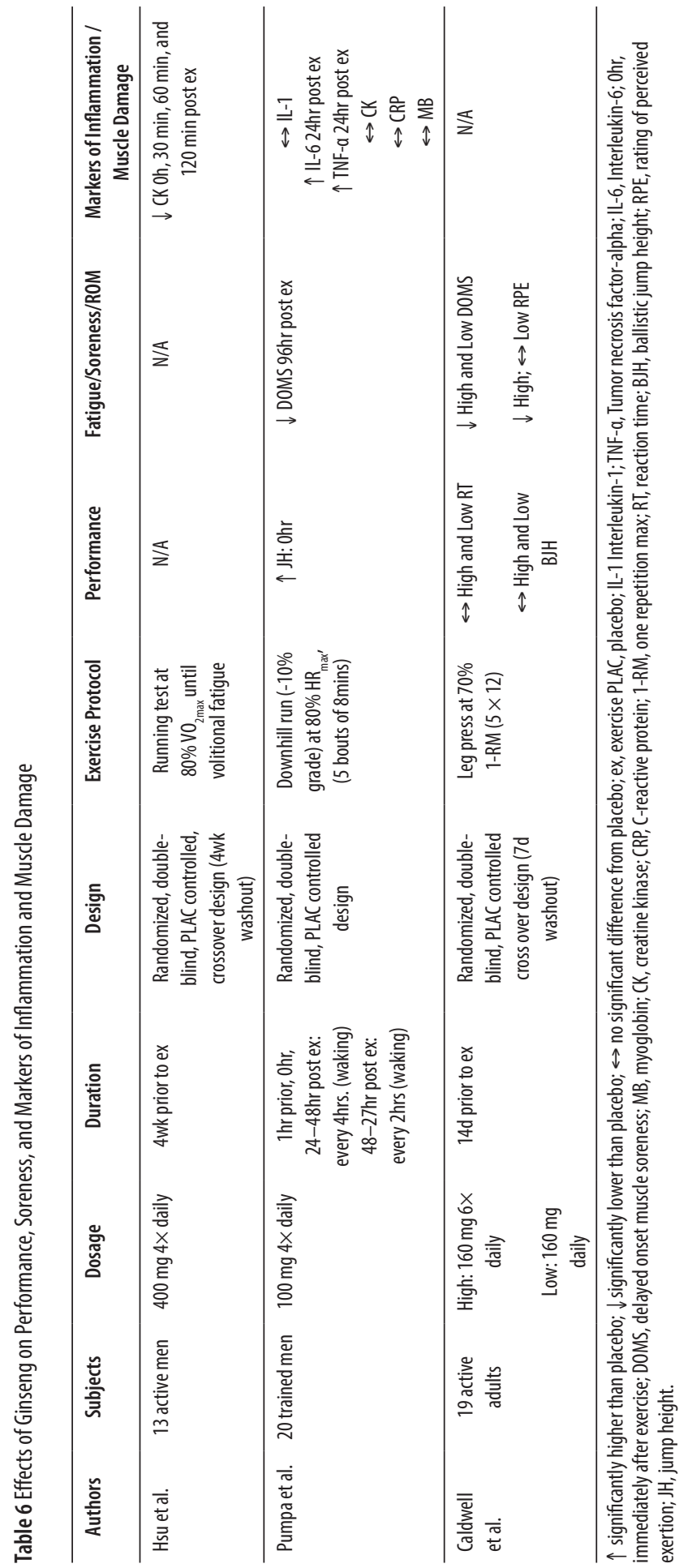




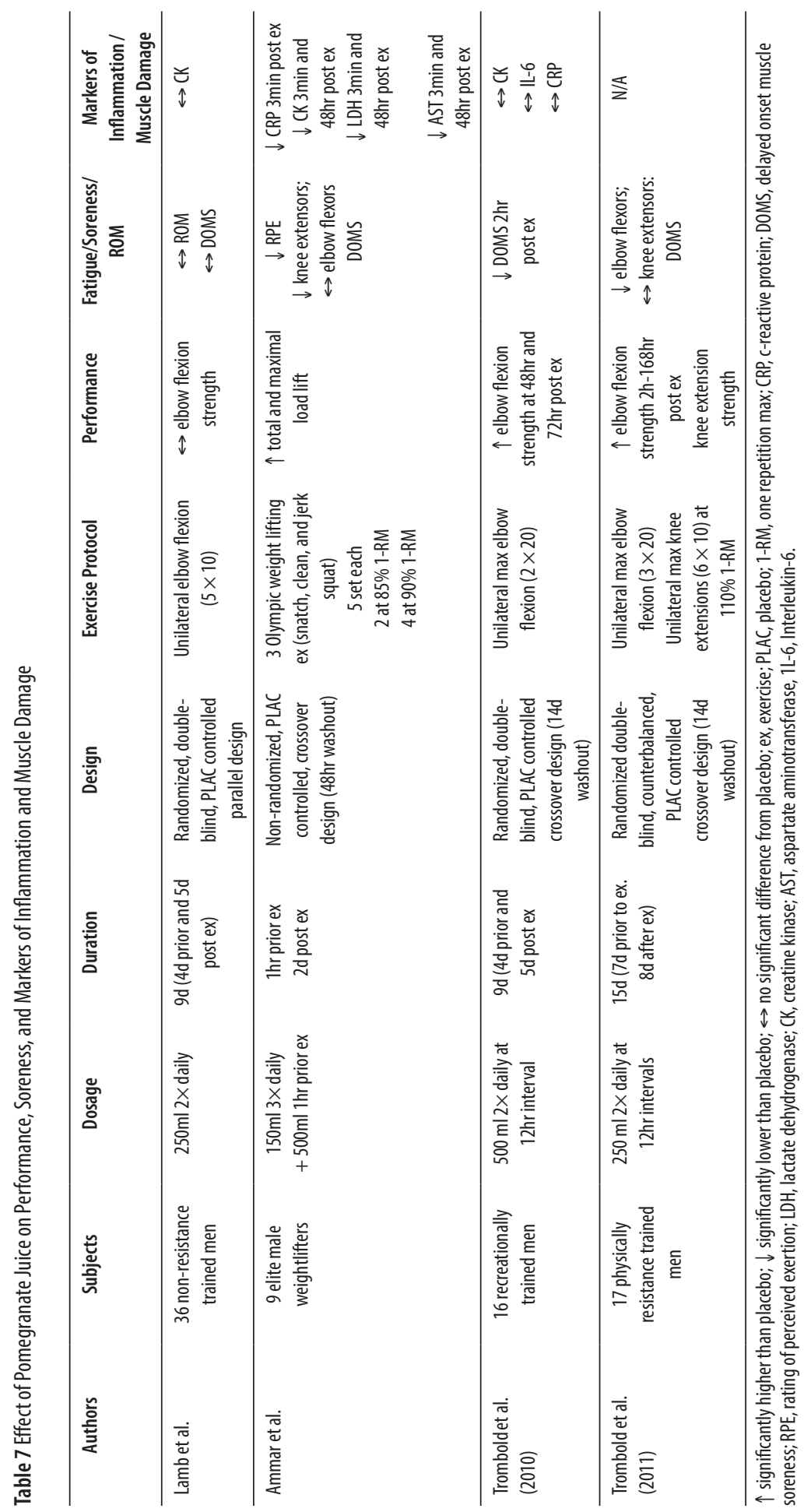




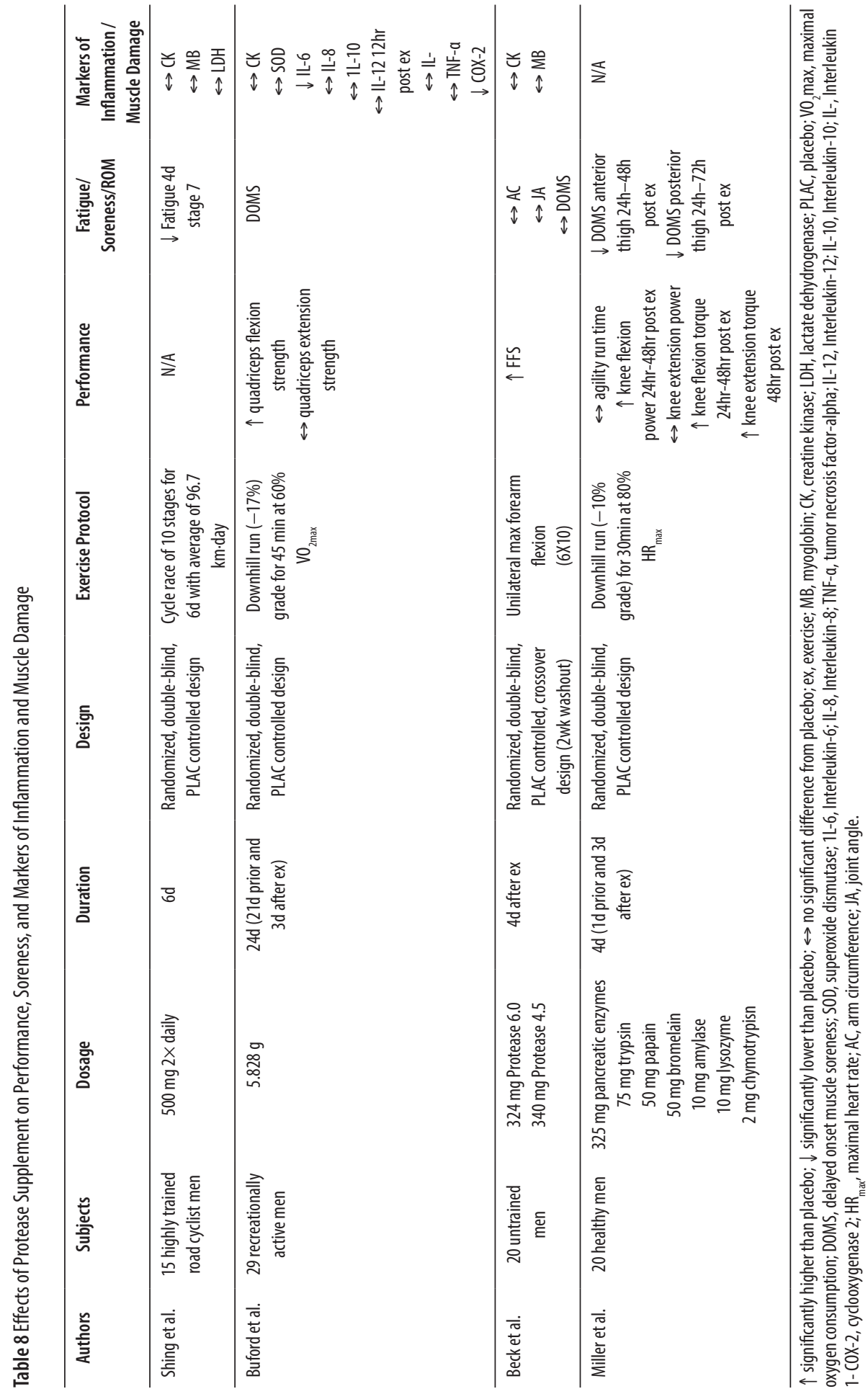

